\title{
IPCRG Consensus statement: Tackling the smoking epidemic - practical guidance for primary care
}

\section{*Onno CP van Schaycka, Hilary Pinnock, Anders Ostremc, John Litt, Ron Tomlinse, Siân Williamsf, Johan Buffels $s^{g}$, Dimitri Giannopoulos ${ }^{\mathrm{h}, \mathrm{i}}$, Svein Henrichsen', Janneke Kaperk, Oleksiy Korzh', Ana Morán Rodriguez ${ }^{m}$, Sehmi Kaw aldip”n, Nick Zw aro, Hakan Yaman ${ }^{p}$}

\footnotetext{
${ }^{a}$ Care and Public Health Research Institute (Caphri), Maastricht University, The Netherlands

${ }^{b}$ Allergy and Respiratory Research Group, Division of Community Health Sciences: GP Section, University of Edinburgh, Scotland

c Gransdalen Legesenter, Oslo, Norway

d Department of General Practice, Flinders University, Flinders Medical Centre, Adelaide, South Australia

e Discipline of General Practice, Western Clinical School, University of Sydney, Australia

f Executive Officer, IPCRG, London, UK

${ }^{9}$ Research Associate and General Practitioner, Department of General Practice, K.U.Leuven, Belgium

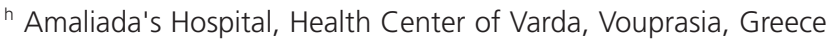

Department of General Practice, Saint Andrews General Hospital, Patras, Greece

' Langbolgen Legesenter, Oslo, Norway

${ }^{k}$ HAG, Care and Public Health Research Institute (Caphri), Maastricht University, The Netherlands

Kharkov, Ukraine

m Bahía de Cádiz Primary Care District, Critical Care and Emergency Devices (DCCU), Spain,

${ }^{n}$ QUIT, London, UK

- University of NSW, General Practice Unit, Fairfield Hospital, New SouthWales, Australia

${ }^{\mathrm{p}}$ Department of Family Medicine, University of Akdeniz, Antalya, Turkey
}

Received 7th February 2008; revised version received 27th June 2008; accepted 21st July 2008; online 5th September 2008

\begin{abstract}
Tobacco use will become the world's foremost cause of premature death and disability within 20 years unless current trends are reversed. Many opportunities to reduce this epidemic are missed in primary care. This Discussion paper from the International Primary Care Respiratory Group (IPCRG) - which reflects the IPCRG's understanding of primary care practitioners' needs - summarises a new approach based on strong evidence for effective interventions.

All primary care health professionals can increase smoking cessation rates among their patients, even when time and resources are limited. Medical and non-medical staff can support patients who choose to quit by providing information, referral to telephone counselling services, and behavioural counselling using motivational interviewing techniques, where resources permit. Drug therapy to manage nicotine dependence can significantly improve patients' chances of quitting successfully, and is recommended for people who smoke 10 or more cigarettes per day. All interventions should be tailored to the individual's circumstances and attitudes.

(c) 2008 General Practice Airways Group. All rights reserved.

OCP van Schayck et al. Prim Care Resp J 2008; 17(3): 185-193.

doi:10.3132/pcrj.2008.00060
\end{abstract}

Keyw ords smoking cessation, primary care, general practice, international, practical guidance, guideline implementation, tobacco control, tobacco dependence, IPCRG

\section{Introduction}

The health benefits of smoking cessation, and the efficacy and cost-effectiveness of medical treatment for tobacco dependence, are well established. ${ }^{1}$ For pharmacological therapies, it has been estimated that one person will successfully quit (achieve 6-month abstinence) for every 6-23

\footnotetext{
* Corresponding author: Dr Onno CP van Schayck, Care and Public Health Research Institute (Caphri), Maastricht University, PO Box 616, 6200 MD, M aastricht, 6212 HH, The Netherlands. Tel: +31 433882152 Email: onno.vanschayck@hag.unimaas.nl
} 
people treated. ${ }^{2}$ Given that approximately half of all longterm smokers will die of a smoking-related illness, ${ }^{3,3 a}$ smoking cessation represents a highly effective preventive strategy compared with other primary prevention interventions.

Health professionals working in primary care can play a vital role in helping their patients quit smoking. The International Primary Care Respiratory Group (IPCRG) has recently published practical guidance on smoking cessation in primary care ${ }^{4}$ as part of its current focus on reducing the impact of smoking on respiratory health.

This IPCRG practical guidance discussion paper is intended for use by primary care health professionals including doctors, nurses and other health workers. It provides an overview of useful tips for incorporating brief, effective smoking cessation interventions into everyday practice, and is supported by a desktop aid. The IPCRG guidance has been developed to help primary care health professionals integrate effective and timeefficient strategies for smoking cessation into their everyday practice. It draws on, but is not intended to replicate, systematic reviews of clinical literature on smoking cessation interventions undertaken elsewhere, ${ }^{5-16}$ nor is it intended to replace national guidelines. ${ }^{6,17-26}$ The guidance development process is outlined at www.theipcrg.org. In summary, no new systematic reviews have been performed; available reviews and guidelines ${ }^{5-26}$ were reviewed, and specific primary care elements were identified and collated during a consensus meeting and then summarised in this paper.

\section{Background: the smoking epidemic}

On current trends, tobacco use may become theyorld's most common cause of premature death and disability within 20 years. ${ }^{1}$ Almost five million people die each year from tobaccorelated causes, and the World Health Organisation (WHO) predicts that this number will double by 2030.' While the combination of population-based strategies and government policies over the past 20 years has substantially reduced the prevalence of smoking in most high-income countries, rates are increasing in low-income and middle-income countries. ${ }^{27}$

Individuals gain significant health benefits by quitting smoking (Table 1). ${ }^{28}$ At the population level, smoking cessation by current adult smokers can be expected to reduce the burden of smoking-related disease within 20-30 years. Meanwhile, efforts to prevent young people taking up the smoking habit should improve population health $30-50$ years from now.

Survey-based studies in some Western populations indicate that over $70 \%$ of current smokers report that they want to quit. 29,30 Attitudes to smoking will be harder to change where it is a cultural norm or where the health benefits of quitting have not been well publicised. Regardless of public health messages, some smokers may not fully realise

\section{Table 1. Health benefits of smoking cessation.}

\begin{tabular}{ll} 
Time since quitting \\
\hline 8 hours & $\begin{array}{l}\text { Blood levels of nicotine and carbon monoxide } \\
\text { reduced by half } \\
\text { Blood oxygen levels return to normal }\end{array}$ \\
\hline 24 hours & Carbon monoxide eliminated from the body \\
\hline 48 hours & $\begin{array}{l}\text { Nicotine eliminated from the body } \\
\text { Taste buds start to recover }\end{array}$ \\
\hline 1 month & $\begin{array}{l}\text { Skin colour improves (loses greyish pallor, } \\
\text { less wrinkled) } \\
\text { Respiratory cilia begin to regenerate } \\
\text { Withdrawal symptoms have stopped }\end{array}$ \\
\hline $3-9$ months & Coughing and wheezing less frequent \\
\hline 5 years & Risk of a heart attack halved, compared with a smoker \\
\hline 10 years & Risk of lung cancer halved, compared with a smoker \\
\hline Adapted from reference 28
\end{tabular}

or accept the health risks of smoking. ${ }^{31,32}$

Nicotine is highly addictive and smokers find it difficult to imagine life without cigarettes. Success rates are low for unajed attempts to quit. ${ }^{33}$ Tobacco dependence is Crecognised by WHO as a chronic relapsing health disorder. ${ }^{34}$ Successful long-term cessation often requires multiple quit attempts, and the experience of relapse can discourage people from continuing to try. Many tobacco users will need significant support to quit successfully and avoid relapse. Effective support includes motivation, advice, counselling, telephone or Internet-based support, and drug treatment where indicated.

\section{Primary care encounters: opportunities for intervention}

Primary health care visits represent important opportunities to promote smoking cessation. Most smokers see their primary care doctor at least once each year, ${ }^{35}$ and many people consider their family doctor as a key influence and source of advice about smoking. ${ }^{36,37}$

Despite effective strategies available to primary care health professionals to help patients quit, we lose many opportunities to counter the smoking epidemic. In countries where smoking is common among health professionals, personal smoking habit is likely to be a strong disincentive to advocate quitting by patients. Even where health professionals believe that smoking is harmful, barriers to intervention include time constraints, lack of skills and resources, health professionals' beliefs that brief advice is unlikely to be effective or that patients are not motivated to quit, and reluctance to jeopardise the doctor-patient 
Table 2. Which smoking cessation strategies are effective?

\section{Effective}

Simple supportive organisational infrastructure - identifying and recording all patients' smoking status, placing smoking cessation literature and posters in waiting areas, promoting quit support services such as telephone counselling. ${ }^{58}$

Brief advice to quit given by a primary care doctor ${ }^{6,8}$

Telephone smoking cessation counselling services ('quit lines') ${ }^{12,59,60}$

Pharmacotherapy for nicotine dependence (Table 5) 5,9,11,15,16 $^{6}$

Face-to-face individual counselling by a healthcare worker trained in behavioural change and not involved in the person's routine clinical care. ${ }^{10}$

\section{Effectiveness not demonstrated*}

Acupuncture $^{14}$

Hypnotherapy

*Insufficient evidence demonstrating greater efficacy than placebo at 6 months' follow-up.

relationship by giving unwelcome advice. ${ }^{38-40}$ In reality, however, patient satisfaction with the consultation is generally higher when smoking is addressed. .1, $^{412}$

\section{Implementation considerations}

For the IPCRG, the immediate challenge to improve the health of people with respiratory disease is to apply known evidence in practice. ${ }^{43}$ As Grol and Buchan have argued, "guidelines do not implement themselves ...[To achieve] complex changes in health care, we need to build bridges between the different approaches to better care - guidelines, performance indicators and feedback; patient empowerment; quality management; organisational change; improving culture, teamwork and leadership in the workplace; and creating the necessary financial incentives." ${ }^{44}$

A number of recent review ${ }^{45-47}$ have examined the challenges of implementing guidelines in clinical practice. Models for improving physician adherence may not be generalisable to other settings where different barriers exist ${ }^{48}$ - a consideration that is particularly relevant to the IPCRG's mission.

Primary care is complex because it involves dealing with a wide diversity of illnesses every day. ${ }^{49,50}$ Primary care doctors must be able to identify, adapt and apply the appropriate intervention to each patient ${ }^{51,52}$ within the person's family and social context and according to health system constraints that apply in their country. ${ }^{53,54}$ Workloads are often high, so there is Constant pressure on health professionals' use of time. ${ }^{55,56}$

In recent years, there has been a shift in emphasis from guideline development to implementing changes in practice that are informed by evidence. ${ }^{51}$ For instance, Sheikh and

Table 3. Tailoring strategies to suit your practice

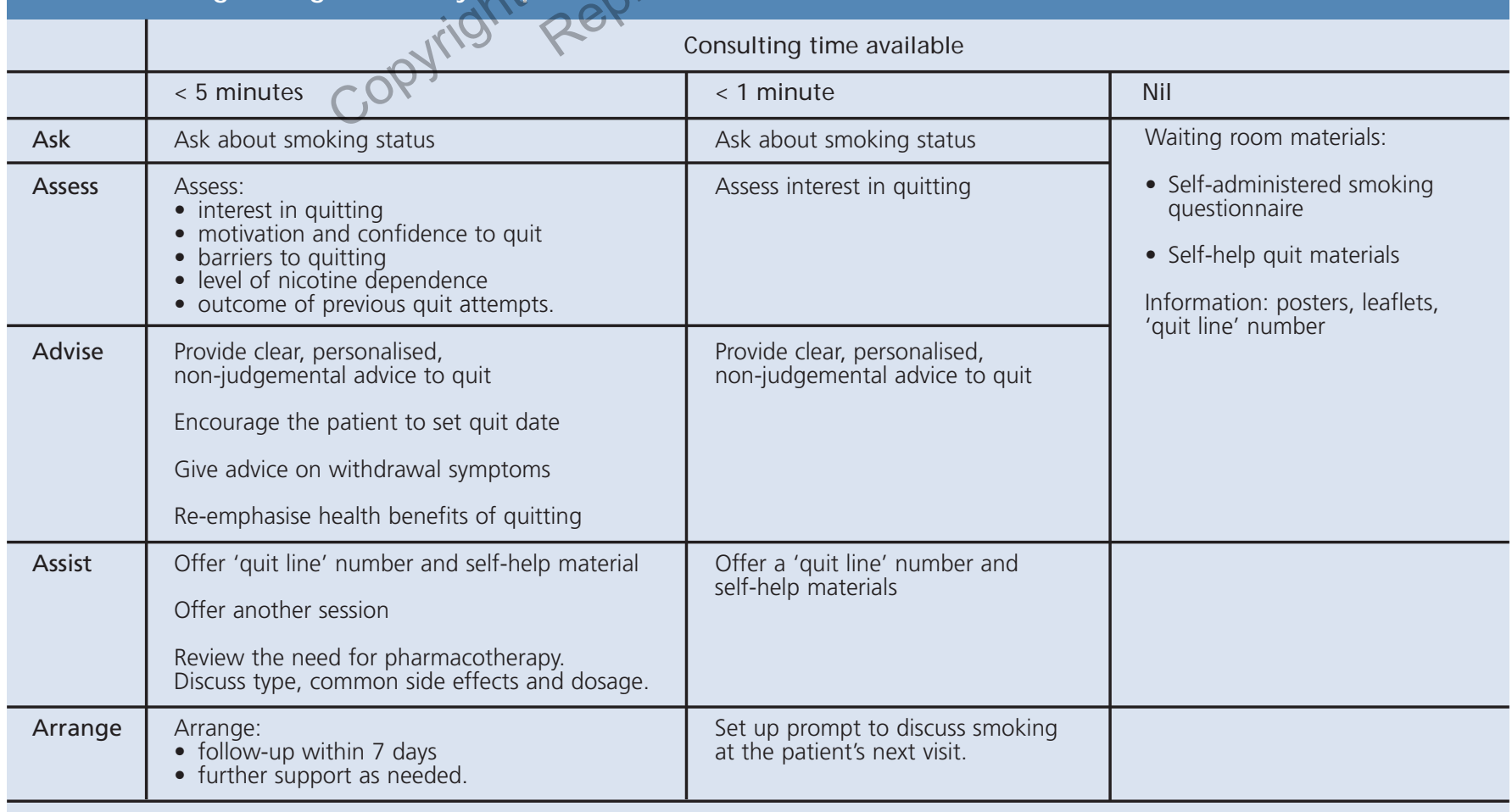


Wallia ${ }^{57}$ have addressed a specific problem for people with diabetes undergoing a prolonged period of fasting.

Practical guidance for the primary care team seeks to use the available evidence to inform the way that care can best be delivered in a local setting.

\section{Key messages from the IPCRG}

Primary care health professionals can support smokers effectively before they are ready to quit, during quit attempts, after quitting and during any relapses. Effective smoking cessation interventions in primary care are based on an awareness of which strategies have been shown to work (Table 2), and on making the most of available resources (Table 3, Figure 1). Key recommendations of the IPCRG guidance are summarised in Table 4 .

\section{Use every opportunity to promote smoke-free living}

Consider whether your practice can implement some or all of these strategies to raise awareness of the benefits of quitting and to offer support:52

- Become a 'no-smoking' practice; institute a smoking ban on practice premises (for staff as well as visitors).

- Place posters and smoking cessation literature in the waiting area.

- Set up systems to prompt you to ask each patient about smoking, routinely record smoking status in medical records, and review it yearly. A combination of identifying and recording all patients' smoking status, displaying smoking cessation literature and posters in waiting areas and promoting telephone counselling services ('quit lines') can double quit rates among your patients, compared with no intervention. ${ }^{58}$

- Opportunistically provide clear, personalised, nonjudgemental advice to quit. For every 100 people who receive brief advice from a primary care doctor to quit smoking, up to three extra people will succeed in quitting for at least six months compared to when no advice is given. ${ }^{6,8}$ Approximately $40 \%$ of smokers make some attempt to quit after such advice. ${ }^{6}$

\section{Support smokers who want to quit}

Whenever smokers indicate they would like to quit, offer your support. Provide reliable verbal and written information and offer consultation to help them in the quit attempt. Refer people to quit lines, where available. Services that actively call people back for follow-up counselling are more effective than those providing only counselling on demand. ${ }^{12,59,60}$ In the UK (and in some other European countries) there are effective specialist smoking cessation services. Smokers referred to these services are Ereated in groups using an approach that aims to foster group communication and support. ${ }^{61}$ This approach is cost effective because groups of 20 or more smokers can be treated together and success rates are Crelativety high. ${ }^{62}$

Prescribe drug treatment for tobacco dependence as Oindicated (Table 5). Pharmacotherapy, particularly when

Figure 1. Choose the level of intervention that suits your practice.

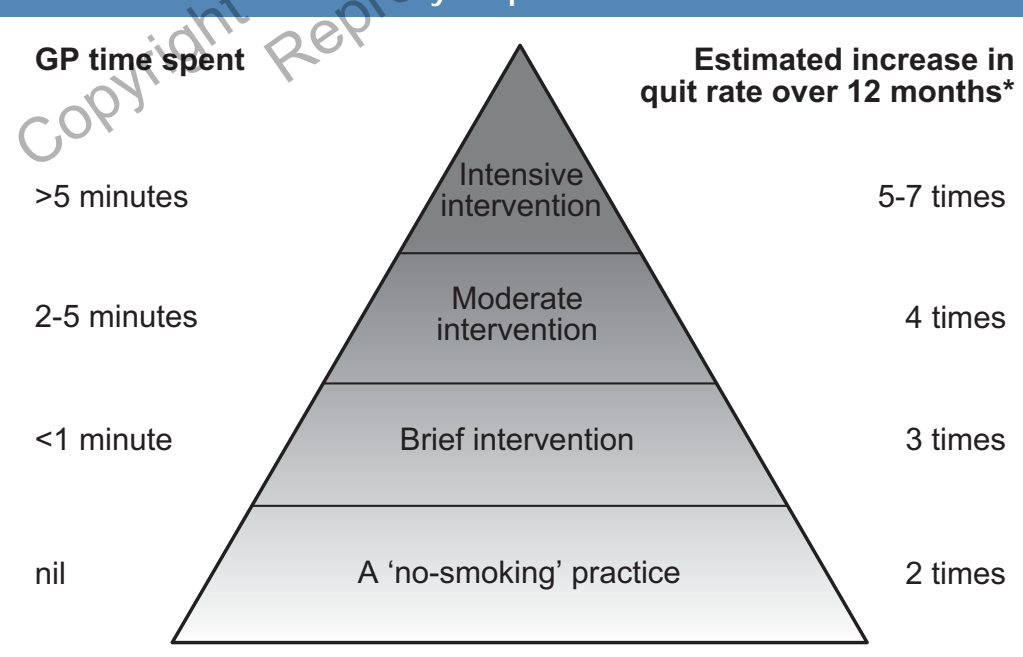

No-smoking practice: identify and record patients' smoking status, place smoking cessation literature and posters in waiting areas, promote quit support services; Brief intervention: discuss smoking status, assess motivation to quit and nicotine dependence, give encouragement to quit, offer advice, information and self-help materials, make a separate appointment to discuss smoking cessation, refer to quit line; Moderate intervention: assess barriers to quitting (quitting history, high-risk situations), briefly explore motivation, ambivalence, barriers and confidence, advise on overcoming dependence, discuss solutions, prescribe pharmacotherapy, offer support and referral to quit line, arrange follow-up; Intensive intervention: in addition to all of the above, offer more intensive exploration of person's motivation, attitudes and confidence, make a quit plan.

Adapted with permission from reference $58 \quad$ *Compared with no intervention 


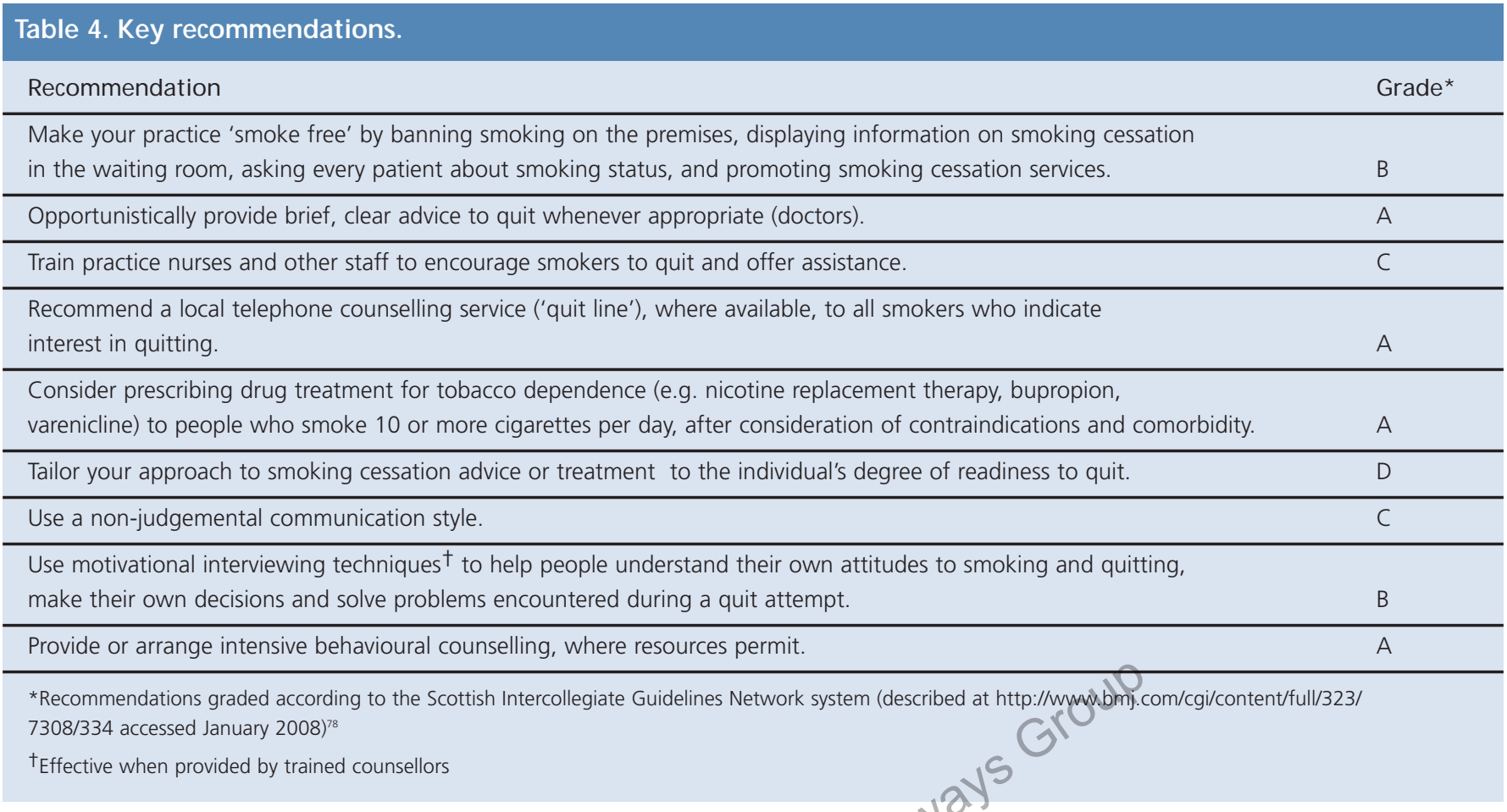

supported by behavioural counselling, significantly improves long-term quit rates compared with no treatment or placebo ${ }^{9 \cdot 11,15,16}$ Offer pharmacotherapy to people who smoke 10 or more cigarettes per day $y^{63,64}$ or who smoke within $30-60$ minutes of waking, after consideration of contraindications and co-morbidity. Selection of pharmacotherapy (is based of clinical suitability and takes account of patient choice ${ }^{65}$

\section{Tailor advice to the person's circumstances}

Smoking cessation advice is likely to be most effective when tailored to suit the individuab Time spent giving specific advice about nicotine withdrawal or drug therapy may be misplaced when offered to a person who is not yet ready to contemplate a quit attempt. A more efficient approach might be to spend a few seconds reinforcing motivation by simply stating the health benefits of quitting. Discussion of 'banning' smoking inside the home must take into account the smoking habits of other family members.

Assess each person's readiness to quit. While the theoretical basis of the "stages of change" model of healthrelated behavioural change (Figure 2$)^{66}$ has recently been questioned, ${ }^{67}$ it remains a useful framework in the consultation to enable you to tailor advice and support. Use the following approach as a guide:

- For people who have not yet thought about quitting (precontemplation stage), state the health benefits of quitting and offer to help as soon as they feel ready to try. Ask permission to discuss their experience of smoking (e.g. habit, degree of nicotine dependence, previous attempts).

- For those contemplating quitting, explore their ambivalenceby helping them identify the pros and cons of quittingoldentify how you can help with a quit plan and offer to provide medical support when they are ready to try.

For those who have decided to quit, give enthusiastic support, help plan the quit plan and set a firm quit date. Offer medical support including pharmacotherapy, and give advice on how to manage nicotine withdrawal. Offer a follow-up visit.

- For those currently attempting to quit, discuss the quit plan and offer help coping with relapse. Arrange a followup visit. Congratulate people when they succeed.

- For those who have quit, offer ongoing support to maintain a smoke-free lifestyle and reinforce the health benefits already achieved.

- For those experiencing relapse, reassure them that they have not 'failed' and have already made progress by gaining the valuable lessons learned from the last quit attempt. Encourage them to use this experience for the next attempt. Reassure them that relapse is common but that people can often quit permanently after more than one attempt.

\section{Use a motivational approach to support quit attempts}

A motivational, non-judgemental style during consultations is more likely to engage patients than a judgemental, directional style. ${ }^{68-71}$ Take the role of an interested, empathising partner who asks questions that explore the smoker's determination and ability to quit. Motivational 
Table 5. Pharmacotherapy for nicotine dependence.

\begin{tabular}{|c|c|c|c|}
\hline Agent & Efficacy & Contraindications & Adverse effects \\
\hline \multirow{3}{*}{$\begin{array}{l}\text { Nicotine replacement therapy } \\
\text { (gum, patches, nasal sprays, } \\
\text { sublingual tablets, lozenges) }\end{array}$} & \multirow{3}{*}{$\begin{array}{l}\text { Abstinence at } 6 \text { months } \\
\text { approximately } 1.5-2 \text { times higher } \\
\text { than for placebo or no nicotine } \\
\text { replacement therapy }\end{array}$} & Acute coronary syndromes & Gastrointestinal disturbances (gum) \\
\hline & & Severe cardiac arrhythmia & \multirow{2}{*}{$\begin{array}{l}\text { Local irritation (patches, nasal } \\
\text { sprays, sublingual tables, lozenges) }\end{array}$} \\
\hline & & Post stroke (acute phase) & \\
\hline \multirow[t]{6}{*}{ Bupropion* } & \multirow{6}{*}{$\begin{array}{l}\text { Abstinence at } 6 \text { months } \\
\text { approximately doubled compared } \\
\text { with placebo }^{15}\end{array}$} & History of seizures & Insomnia \\
\hline & & Anorexia nervosa & Dry mouth \\
\hline & & Bulimia & Nausea \\
\hline & & Bipolar disorder & Headache \\
\hline & & Severe liver impairment & Constipation \\
\hline & & Pregnancy & Agitation \\
\hline \multirow[t]{6}{*}{ Nortriptyline ${ }^{\dagger}$} & \multirow{6}{*}{$\begin{array}{l}\text { Abstinence at } 6 \text { months } \\
\text { approximately doubled compared } \\
\text { with placebo }^{15}\end{array}$} & Recent myocardial infarction & Sedation \\
\hline & & Benign prostatic hyperplasia & Dry mouth \\
\hline & & History of urinary retention & Light-headedness \\
\hline & & & Cardiac arrhythmia \\
\hline & & & $\begin{array}{l}\text { Nausea } \\
\text { Visual disturbance }\end{array}$ \\
\hline & & & Benign prostatic hyperplasia \\
\hline \multirow[t]{5}{*}{ Varenicline } & \multirow{5}{*}{$\begin{array}{l}\text { Abstinence at } 12 \text { months } \\
\text { approximately three times higher } \\
\text { than for placebo }{ }^{16}\end{array}$} & & Nausea \\
\hline & & & Insomnia \\
\hline & & & Abnormal dreams \\
\hline & & & Headache \\
\hline & & & Gastrointestinal upset \\
\hline
\end{tabular}

Figure 2. The cycle of change.

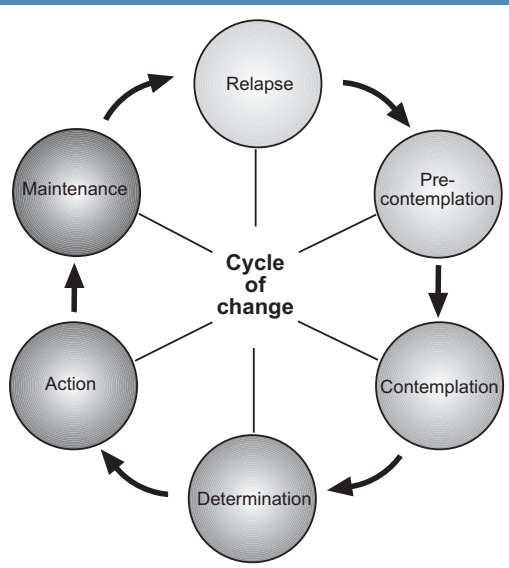

Pre-contemplation: person has not yet considered quitting; Contemplation: person is considering quitting but still very ambivalent; Determination: person is ready to attempt quitting; Action: quit plan is underway; Maintenance: person has quit; Relapse: person has recommenced smoking.

Adapted with permission from reference 64 interviewing acknow ledges that the patient, not the doctor, is responsible for changing behaviour. There are four key principles: ${ }^{72}$

1. Acknowledge the person's behaviour as his or her own personal choice.

2. Let patients decide the degree to which smoking is a problem for them.

3. Avoid argumentation and confrontation.

4. Encourage the person to discuss the advantages and disadvantages of making a quit attempt, as they see them. Use this discussion to highlight inconsistencies in the smoker's beliefs.

A useful framework for integrating all of the evidencebased strategies for smoking cessation in primary care is based on the principles of asking, assessing, advising, assisting and arranging - the 'five As' (Table 3). This framew ork complements the motivational approach based on the cycle of change and has been successfully applied in practice to guide patients through and beyond their quit attempt. ${ }^{6,26,63}$ 


\section{Make the most of available time}

Effective strategies can be incorporated into routine primary care encounters, even where available consultation time is limited (Figure 1). Before health workers even mention smoking, a practice can already have sent patients a strong visual "quit smoking" message through posters and literature in the waiting room. ${ }^{73}$

Brief advice to quit takes less than a minute. In 2-5 minutes (particularly if working in co-operation with other team members), it is possible to ask a patient about current smoking status, briefly assess the person's desire to quit and degree of nicotine dependence, identify the main barriers to quitting and suggest some strategies to overcome them, set a quit date, provide self-help materials, and arrange follow-up or referral to 'quit' services.

Recruit all staff members to help motivate patients to quit smoking. Suitable roles might involve asking about smoking status whenever appropriate, offering literature, and informing people about useful local websites and services such as telephone counselling.

Where resources permit, offer more intensive intervention (for example, behavioural support in sessions at least 30 minutes long, or shorter sessions in combination with followup appointments and pharmacological support). These types of intensive support may increase rates of successful quitting (at least six months' abstinence) by up to $19 \%$ more than for groups not receiving these forms of support. ${ }^{6}$

\section{Special risk groups}

\section{Pregnant women}

Smoking cessation interventions are particularly effective during pregnancy because mothers are usually aw are of the potential harm to their baby? Post-partum follow-up reduces relapse rates.

Nicotine replacement therapy may be appropriate (subject to local prescribing regulations), given that the dose of nicotine is lower than the dose from cigarettes. However, there are limited safety data for pregnancy, so the benefits must be weighed against potential adverse effects. Most national smoking cessation guidelines conclude that the benefits of treatment outweigh the risks and therefore recommend using some form of NRT during pregnancy. However, bupropion and varenicline are not recommended in pregnancy.

Adolescents

Approximately $80 \%$ of smokers begin smoking during their teenage years. Nicotine dependence develops very rapidly in teenagers. Among teenagers who lose control over their tobacco use, $10 \%$ do so within two days of inhaling from a cigarette for the first time, and $50 \%$ by the time they are smoking seven cigarettes per month. ${ }^{74}$

Teenagers care more about the immediate benefits to their appearance, current well-being and financial status than about future health gains. Therefore, it is useful to emphasise the following benefits of quitting in addition to long-term health: better physical appearance including teeth; avoiding bad breath; cost savings (e.g. calculate the amount spent per year on cigarettes); better sexual performance; avoidance of toxic chemicals in cigarettes; and ability to control own behaviour.

People living with mental illness

Compared with the general population, smoking rates are higher among people with mental illness, and heavy smoking is common among those with psychotic disorders. ${ }^{75}$ Bupropion and nortriptyline are effective in assisting smoking cessation in people with and without a history of depression. ${ }^{76}$ Carefully consider potential interactions with other antidepressant medications, including lowering of the seizure threshold. Varenicline is not recommended in patients with significant psychological illness because there is a lack of evidence for its efficacy and safety in this group. ${ }^{65}$

\section{Conclusions}

All primary care health professionals should consider smoking as an important Chealth issue for intervention, and should manáge tobacco dependence as a chronic relapsing medical disorder All can make an effective contribution by helping existing adult smokers to quit and encouraging teenagers not to begin smoking. Evidence-based smoking cessation strategies can be incorporated into any primary care practice, tailored to the practice style, the patient demographics, and the time and resources available.

Cultural issues will differ between primary care settings, depending on the country and its cultural norms, the sociocultural backgrounds of health professionals, and the socioeconomic status of their patients. Independent of their desire to quit, groups who are socioeconomically deprived face additional challenges and may need more support to quit and avoid relapse. In Europe, for instance, quit rates seen over the past 10 years have been higher among groups with higher socioeconomic and education status. ${ }^{77}$ Those groups that have not yet benefited from the secular trend towards a smoke-free lifestyle stand to benefit most from well-directed support from their primary care health professionals.

Accordingly, this IPCRG guidance is offered as a set of suggested strategies based on those which have proved effective in their original socio-cultural settings. In the absence of supportive government policies, implementation of the guidance will be particularly challenging for individual primary care health professionals.

\section{Conflict of interest}

The authors have declared that there are no directly relevant conflicts of interest in relation to this article. 


\section{Acknow ledgements}

Samantha Louw provided administrative assistance.

Jennifer Harman, Meducation Australia, assisted in drafting the manuscript.

\section{Funding}

The guidance development process used to produce this consensus statement was supported by an unrestricted educational grant from Pfizer Inc (Europe) awarded to the IPCRG. The IPCRG used this unrestricted grant to provide reimbursement for travel and accommodation costs incurred by the authors.

\section{References}

1. da Costa e Silva V, ed. Tools for advancing tobacco control in the XXIst century: policy recommendations for smoking cessation and treatment of tobacco dependence. Tools for public health. Geneva: World Health Organization, 2003.

2. Watts SA, Noble SL, Smith PO, Disco M. First-line pharmacotherapy for tobacco use and dependence. J Am Board Fam Pract 2002;15:489-97.

3. Edwards R. The problem of tobacco smoking. BMJ 2004;328:217-19.

3a. Gates TJ. Screening for cancer: evaluating the evidence. Am Fam Physician 2001;63:513-22.

4. International Primary Care Respiratory Group. Tackling the smoking epidemic. International guidance on smoking cessation in primary care (available at http://www.theipcrg.org/smoking/index.php).

5. Abbot NC, Stead LF, White AR, Barnes J. Hypnotherapy for smoking cessation. Cochrane Database Syst Rev 1998, Issue 2. Art. No.: CD001008. DOI: 10.1002/14651858.CD001008.

6. West R, McNeill A, Raw M. Smoking cessation guidelines for health professionals: an update. Thorax 2000;55:987-99.

7. Lumley J, Oliver SS, Chamberlain C, Oakley L. Interventions for promoting smoking cessation during pregnancy. Cochrane Database Syst Rev 2004, 1ssue 4. Art. No.: CD001055. DOI: 10.1002/14651858.CD001055.pub2

8. Lancaster T, Stead LF. Physician advice for smoking cessation, Cochrane Database Syst Rev 2004, Issue 4. Art. No.: CD000165.

9. Silagy C, Lancaster T, Stead L, M ant D, Fowler G. Nicotine replacement therapy for smoking cessation. Cochrane Database Syst Rev 2004, Issue 3. Art. No.: CD000146. DOI: 10.1002/14651858.CD000146.pub2

10. Lancaster T, Stead LF. Individual behavioural counselling for smoking cessation. Cochrane Database Syst Rev 2005, Issue 2. Art. No.: CD001292. DOI: 10.1002/14651858.CD001292.pub2.

11. Wu P, Wilson K, Dimoulas P, Mills EJ. Effectiveness of smoking cessation therapies: a systematic review and meta-analysis. BMC Public Health 2006;6:300.

12. Stead LF, Perera R, Lancaster T. Telephone counselling for smoking cessation. Cochrane Database Syst Rev 2006, Issue 3. Art. No.: CD002850. DOI: 10.1002/14651858.CD002850.pub2.

13. Ranney L, Melvin C, Lux L, MCClain E, Lohr KN. Systematic review: smoking cessation intervention strategies for adults and adults in special populations. Ann Intern Med 2006;145:845-56.

14. White AR, Rampes $H, C a m p b e l l ~ J L$. Acupuncture and related interventions for smoking cessation. Cochrane Database Syst Rev 2006, Issue 1. Art. No.: CD000009. DOI: 10.1002/14651858.CD000009.pub2.

15. Hughes J, Stead L, Lancaster T. Antidepressants for smoking cessation. Cochrane Database Syst Rev 2007, Issue 1. Art. No.: CD000031. DOI: 10.1002/14651858.CD000031.pub3.

16. Cahill K, Stead LF, Lancaster T. Nicotine receptor partial agonists for smoking cessation. Cochrane Database Syst Rev 2007, Issue 1. Art. No.: CD006103.

17. World Health Organization (WHO) European Partnership Project to Reduce Tobacco Dependence. WHO evidence based recommendations on the treatment of tobacco dependence. Copenhagen: WHO, 2001.

18. Zwar N, Richmond R, Borland R, Stillman S, Cunningham M, Litt J. Smoking cessation guidelines for Australian general practice. Canberra; Commonwealth of Australia, 2006.

19. Gailly J. Arrêter de Fumer / Stoppen met Roken. 2005. (http://www.ssmg.be/new/files/RBP_Tabac.pdf and http://www.wvvh.be/ Page. aspx?id=945 accessed December 2007)

20. Chavannes NH, Kaper J, Frijling BD, Van der Laan JR, Jansen PWM, Guerrouj S, Drenthen AJM, Bax W, W ind LA. NHG-Standaard Stoppen met roken. Huisarts en Wetenschap 2007;50:306-14.

21. Sosial- og helsedirektoratet, Røykeavvenning i primærhelsetjenesten. June 2004 (http://www.shdir.no/vp/multimedia/archive/00001/IS-1171_1860a.pdf accessed December 2007)

22. Torrecilla García M, Plaza Martin MD, Ruano García R. Consejo medico e intervención minima sitematizada. En: Manual de Prevención y Tratamiento del Tabaquismo. Capítulo IV. Barrueco Ferrero M et al. 2006.

23. Barchilón Cohen $V$, Morán Rodríguez $A$, Espigares Jiménez $M$, et al. Tabaquismo. Abordaje en Atención Primaria. Sociedad Andaluza de Medicina Familiar y Comunitaria (SAM FYC). (http://www.cica.es/ samfyc-gr Accessed December 2007)

24. T.C. Saglik Bakanligi Birinci Basamaga Yönelik Tani ve Tedavi Rehberleri 2003. (http://www.saglik.gov.tr/aile/doc/1_basamak_t\% C4\% B1bbi_ted_kitap.pdf accessed December 2007)

25. Department of Veterans Affairs, Department of Defense. Clinical practice guideline for the management of tobacco use. Washington, DC: US Department of Defense, 2004.

26. Fiore MC, Bailey WC, Cohen SJ, et al. Treating Tobacco use and Dependence. Clinical, Practice Guideline. Rockville, US: Department of Health and Human Services, 2000.

27. Wha P, Chalouipka FJ, Corrao M, Binu J. Reducing the burden of smoking worldwide: effectiveness of interventions and their coverage. Drug Alcohol Rev 2006;25:597-609.

28. Action on Smoking and Health. Factsheet Number 11. Stopping Smoking ASH 2007 (http://www.newash.org.uk/ash_xwu8d7wa.htm accessed November 2007).

29. Owen N, Wakefield M, Roberts L, Esterman A. Stages of readiness to quit smoking: population prevalence and correlates. Health Psychol 1992;11:41317.

30. Lader D. Smoking-related Behaviour and Attitudes, 2006. A report on research using the National Statistics Omnibus Survey produced on behalf of the Information Centre for health and social care. Omnibus Survey Report No. 32. New port: Office for National Statistics, 2007.

31. O'Connor RJ, McNeill A, Borland R, et al. Smokers' beliefs about the relative safety of other tobacco products: findings from the ITC collaboration. Nicotine Tob Res 2007;9:1033-42.

32. Yong HH, Borland R, Siahpush M. Quitting-related beliefs, intentions, and motivations of older smokers in four countries: findings from the International Tobacco Control Policy Evaluation Survey. Addict Behav 2005;30:777-88.

33. Baillie AJ, Mattick RP, Hall W. Quitting smoking: estimation by meta-analysis of the rate of unaided smoking cessation. Aust J Public Health 1995;19:129-31.

34. World Health Organization. International statistical classification of diseases and related health problems (10th Revision). Geneva: WHO, 1992.

35. Zwar NA, Richmond RL. Role of the general practitioner in smoking cessation. Drug Alcohol Rev 2006;25:21-6.

36. Richmond R, Kehoe L, Heather N, Wodak A, Webster I. General practitioners' promotion of healthy life styles: what patients think. Aust NZ J Pub Health 1996;20:195-200.

37. Duaso $M$, Cheung $P$. Health promotion and lifestyle advice in general practice: what do patients think? J Adv Nurs 2002;39:472-9.

38. Coleman T, Wilson A. Anti-smoking advice in general practice consultations: general practitioners' attitudes, reported practice and preconceived problems. $\mathrm{Br}$ J Gen Pract 1996;46:87-91. 
39. Twardella $\mathrm{D}$, Brenner $\mathrm{H}$. Lack of training as a central barrier to the promotion of smoking cessation: a survey among general practitioners in Germany. Eur J Public Health 2005;15:140-5.

40. Edwards D, Freeman T, Litt J, Roche A. GPs' confidence in and barriers to implementing smoking cessation activities: Compared to dentists, dental hygienists and pharmacists. Aust J Primary Health 2006;12:117-25.

41. Barzilai D, Goodwin M, Stange K. Does health habit counseling affect patient satisfaction? Prev Med 2001;33:595-9.

42. Sciamanna $C$, Novak $S$, Houston T, Gramling R, M arcus B. Visit satisfaction and tailored health behavior communications in primary care. Am J Prev Med 2004;26:426-30.

43. Tomlins R. International Primary Care Respiratory Group (IPCRG) Guidelines: Dissemination and Implementation - a proposed course of action. Prim Care Respir J 2006;15:71-4. doi:10.1016/j.pcrj.2005.11.004

44. Grol R, Buchan H. Clinical guidelines: what can we do to increase their use? MJA 2006;185:301-02

45. Solberg LI, Brekke ML, Fazio CJ, et al. Lessons from experienced guideline implementers: attend to many factors and use multiple strategies. Jt Comm J Qual Improv 2000;26:171-88.

46. Dennis SM, Edwards S, Partridge M R, Pinnock HJ, Qureshi S. The dissemination of the British Guideline on the Management of Asthma 2003. Respir Med 2004;98:832-7.

47. Grimshaw JM, Thomas RE, MacLennan G, et al. Effectiveness and efficiency of guideline dissemination and implementation strategies. Health Technol Assess 2004;8:iii-iv,1-72.

48. Cabana MD, Rand CS, Powe NR, et al. Why don't physicians follow clinical practice guidelines? A framework for improvement. JAMA 1999;282:1458-65.

49. Schoen C, Osborn R, Huynh PT, Doty M, Peugh J, Zapert K. On the front lines of care: primary care doctors' office systems, experiences, and views in seven countries. Health Aff (Millwood) 2006;25:w555-71.

50. Britt H, Miller GC, Charles J, Pan Y, et al. General practice activity in Australia 2005-06. Australian Institute of Health and Welfare and the University of Sydney 2007.

51. Glasziou P, Haynes P. The paths from research to improved health outcomes. Evid Based Med 2005;10:4-7.

52. Royal Australian College of General Practice. Putting prevention into practice (2nd edition). Melbourne: RACGP, 2006

53. Straus S, Jones, G What has evidence based medicine done for us? BMJ 2004; 329:987-8.

54. Groves T, Wagner EH. High quality care for people with chronic diseases. BMJ 2005;330:609-10.

55. Yarnall KSH, Pollak KI, Østbye T, Krause KM, M ichener L. Primary care: is there enough time for prevention? Am J Public Health 2003;93:635-41.

56. Østbye T, Yarnall KS, Krause KM, Pollak KI, Gradison M, M ichener JL. Is there time for management of patients with chronic diseases in primary care? Ann Fam Med 2005;3:209-14.

57. Sheikh A, Wallia S. Ramadan fasting and diabetes. BMJ 2007;335:613-14.

58. Litt J. How to provide effective smoking cessation advice in less than a minute without offending the patient. Aust Fam Physician 2002;31:1087-94.

59. Ossip-Klein D, Mclntosh S. Quitlines in North America: evidence base and application. Am J Med Sci 2003;326:201-05

60. Borland R, Segan CJ. The potential of quitlines to increase smoking cessation. Drug Alcohol Rev 2006;25:73-8.

61. Hajek P. Helping smokers to overcome tobacco withdrawal: background and practice of withdrawal orientated therapy. In:Richmond R, editor. Interventions for smokers an international perspective. Baltimore: Williams and Wilkins; 1994. p. 29-46.

62. Bauld L, Chesterman J, Judge K, Pound E, Coleman T. English Evaluation of Smoking Cessation Services (EESCS). Impact of UK National Health Service smoking cessation services: variation in outcomes in England. Tob Control 2003;12:296-301.

63. Raw M, European Partnership to Reduce Tobacco Dependence. WHO evidence based recommendations on the treatment of tobacco dependence. World Health Organization, 2001.

64. Aveyard P, West R. Managing smoking cessation. BMJ 2007;335;37-41.

65. Zwar N, Richmond R, Borland R, et al. Smoking cessation pharmacotherapy: an update for health professionals. Melbourne: Royal Australian College of General Practitioners, 2007.

66. Prochaska JO, DiClemente CC. Stages and processes of self-change of smoking: toward an integrative model of change. J Consult Clin Psychol 1983;51:390-5.

67. West R, Sohal T. "Catastrophic" pathways to smoking cessation: findings from a national survey. BMJ 2006;332:458-60.

68. Miller WR, Rollnick S. Motivational interviewing, preparing people to change addictive behavior. New York: The Guildford Press, 1991.

69. Rubak S, Sandbaek A, Lauritzen T, Christensen B. Motivational interviewing: a systematic review and meta-analysis. Br J Gen Pract 2005;55:305-12.

70. Rollnick S, Butler CC, McCambridge J, Kinnersley P, Elwyn G, Resnicow K. Consultations about changing behaviour. BMJ 2005;331:961-3.

71. Soria R, Legido A, Escolano C, López Yeste A, Montoya J. A randomised controlled trial of motivational interviewing for smoking cessation. $\mathrm{Br}$ J Gen Pract 2006;56:768-74.

72. Litt J. Smoking and GPs: time to cough up: successful interventions in general practice. Aust Fam Physician 2005;34:425-9.

73. Persson LG, Lindström U. [A waiting room inquiry about smoking resulted in more smoking cessation referrals. Unexpected many smokers quit smoking] Lakartidningen 2007;104:2427-30.

74. DiFranza JR, Savageau JA, Fletcher K, et al. Susceptibility to nicotine dependence: the Development and Assessment of Nicotine Dependence in Youth 2 study. Pediatrics 2007;120:e974-83.

75. McNeil A. Smoking and mental health - a review of the literature. London: Smoke Free London Programme, 2001.

76. Roddy E. Bupropion and other non-nicotine pharmacotherapies. BMJ 2004;328:509-11.

77. Janson C, Künzli N, de Marco R, et al. Changes in active and passive smoking in the European Community Respiratory Health Survey. Eur Respir J 2006;27:517-24.

78. Harbour R, Miller J. A new system for grading recommendations in evidence based guidelines. BMJ 2001;323:334-6.

\section{Available online at http://w w w.thepcrj.org}

